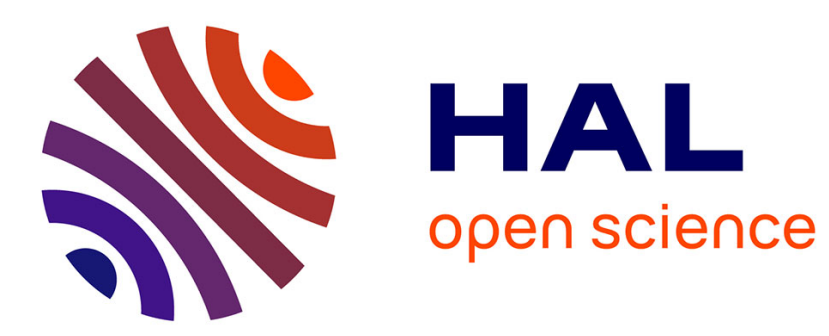

\title{
PSC and volcanic aerosol observations during EASOE by UV-visible ground-based spectrometry
}

\author{
Alain Sarkissian, Jean-Pierre Pommereau, Florence Goutail, Esko Kyro
}

\section{To cite this version:}

Alain Sarkissian, Jean-Pierre Pommereau, Florence Goutail, Esko Kyro. PSC and volcanic aerosol observations during EASOE by UV-visible ground-based spectrometry. Geophysical Research Letters, 1994, 21 (13), pp.1319-1322. 10.1029/93GL03072 . insu-03354824

\section{HAL Id: insu-03354824 \\ https://hal-insu.archives-ouvertes.fr/insu-03354824}

Submitted on 28 Dec 2021

HAL is a multi-disciplinary open access archive for the deposit and dissemination of scientific research documents, whether they are published or not. The documents may come from teaching and research institutions in France or abroad, or from public or private research centers.
L'archive ouverte pluridisciplinaire HAL, est destinée au dépôt et à la diffusion de documents scientifiques de niveau recherche, publiés ou non, émanant des établissements d'enseignement et de recherche français ou étrangers, des laboratoires publics ou privés. 


\title{
PSC and volcanic aerosol observations during EASOE by UV-visible ground-based spectrometry
}

\author{
Alain Sarkissian, Jean-Pierre Pommereau, and Florence Goutail \\ Service d'Aéronomie, Verrières-le-Buisson, France
}

Esko Kyro

Finnish Meteorological Institute, Sodankylā, Finland

Abstract. Twilight sky colour measurements were made using ground-based UV-visible SAOZ spectrometers at four stations along the Arctic circle during EASOE. The results show that volcanic aerosol from the Pinatubo eruption of June 1991 first appeared above the Arctic in September 1991. The aerosol layer thickened progressively during the autumn and had spread to all four stations, outside in the very low stratosphere, as well as inside the polar vortex, by mid-January. For the rest of the campaign, to mid-March, little further change was seen. The aerosol would have masked any PSCs that may have occurred at altitudes less than $22 \mathrm{~km}$. However, PSCs at higher altitudes should have been detected, had their optical thickness exceeded 0.01 . Only one was recorded during EASOE: on 28-29 December 1991 , in contrast to their frequent occurrence in January and early February 1990

\section{Introduction}

Polar stratospheric clouds (PSCs) and aerosol are important features of the atmosphere, providing sites for heterogeneous chemical reactions that may be precursors to ozone loss. They can be monitored from the ground using a colour index derived from UV-visible spectrometers recording zenith sky spectra in twilight. This index has been used to interpret observations made in 1990 at Kiruna $\left(68^{\circ} \mathrm{N}\right.$, $21^{\circ} \mathrm{E}$ ) in Sweden [Sarkissian et al., 1991] and four years of observations (1988-1991) made at Dumont d'Urville in Antarctica [Sarkissian et al., 1992]. As shown by a radiative transfer model, the colour of the zenith sky during twilight is shifted towards the red by high altitude $(22-28 \mathrm{~km})$ thin layers of PSCs or volcanic aerosol, and towards the blue by low altitude $(12-20 \mathrm{~km})$ thick scattering layers.

Four UV-visible SAOZ diode array spectrometers were deployed in the Arctic during EASOE: at Sodankylä in Finland $\left(67^{\circ} \mathrm{N}, 27^{\circ} \mathrm{E}\right)$, at Scoresbysund in Greenland $\left(71^{\circ} \mathrm{N}\right.$, $22^{\circ} \mathrm{W}$ ), on board the Norwegian weather ship Polarfront $\left(66^{\circ} \mathrm{N}, 2^{\circ} \mathrm{E}\right)$ and at Zhigansk in Siberia $\left(67^{\circ} \mathrm{N}, 123^{\circ} \mathrm{E}\right)$. The results of these continuous observations are discussed.

\section{Colour Index Method}

The SAOZ diode array spectrometer is a broad-band $(300-600 \mathrm{~nm})$, medium resolution $(0.6 \mathrm{~nm})$ instrument

Copyright 1994 by the American Geophysical Union.

Paper number 93GL03072

0094-8534/94/93GL-03072\$03.00
[Pommereau and Goutail, 1988], designed to make measurements of total ozone and of $\mathrm{NO}_{2}$ twice a day at twilight. It records spectra of the zenith sky every five minutes while there is sufficient light, that is until the solar zenith angle (SZA) exceeds $94-95^{\circ}$, depending on the cloud cover. The spectra are corrected for the results of molecular absorption by $\mathrm{O}_{3}, \mathrm{NO}_{2}, \mathrm{O}_{4}$ and $\mathrm{H}_{2} \mathrm{O}$ using an iterative differential procedure. The residual twilight spectra depend only on the scattering properties of the atmosphere. They are very sensitive to the presence or absence of layers of scattering particles at various altitudes.

We define the colour index, CI, of the zenith sky as the ratio of the fluxes observed simultaneously at 550 and $350 \mathrm{~nm}$. The uncertainty in CI arising from uncertainty in correcting for ozone absorption at $550 \mathrm{~nm}$ is less than $1 \%$ [Goutail et al., 1992]. CI is strongly dependent on the scattering properties of the lower troposphere at moderate SZA and, since the mean height of primary scattering increases with increasing SZA, of the upper troposphere at twilight. Blue skies have small CI. Clouds redden the zenith sky, giving larger CI. When multiple scattering is greatly enhanced, as in snow showers, very large CI are found.

Generally in twilight, $\mathrm{CI}$ is found to remain constant for SZA between $90^{\circ}$ and $93^{\circ}$, provided the tropospheric cloud cover does not vary too much. However, large increases and decreases have been recorded with no change in tropospheric cloud cover, principally in winter. These changes must be caused by scatterers in the stratosphere, since the troposphere is not directly illuminated. We interpret such changes as indicators of the presence of PSCs. We define a twilight variation index, $\Delta \mathrm{CI}(\mathrm{SZA})$, as $\mathrm{CI}(\mathrm{SZA}) / \mathrm{CI}\left(90^{\circ}\right)$.

A simple radiative transfer model was used to assess the effects of scattering layers in the stratosphere on $\Delta \mathrm{CI}$ measured at ground-level [Sarkissian et al., 1991]. The atmosphere is treated as a series of spherical shells each $1 \mathrm{~km}$ thick. It has been found that high altitude $(22-28 \mathrm{~km})$ and geometrically thin $(1-5 \mathrm{~km})$ scatterers cause the zenith sky to redden as the SZA increases $(\Delta \mathrm{CI}>1) . \Delta \mathrm{CI}\left(92.5^{\circ}\right)$ increases with increases in altitude and in optical thickness of the scattering layer, but decreases as the geometrical thickness of the layer increases. Low altitude $(12-20 \mathrm{~km})$ and geometrically thick $(5-10 \mathrm{~km})$ scattering layers make the zenith sky more blue as SZA increases $(\Delta \mathrm{CI}<1)$, and $\Delta \mathrm{CI}\left(92.5^{\circ}\right)$ decreases with increases in the optical and geometrical thicknesses of the scattering layer.

\section{Observations in northern Scandinavia, 1990-1992.}

Figure 1 shows data from January 1990 to mid-August 1992 (recorded for the first month at Kiruna, thereafter at Sodankylä). The three panels are, from top to bottom, 


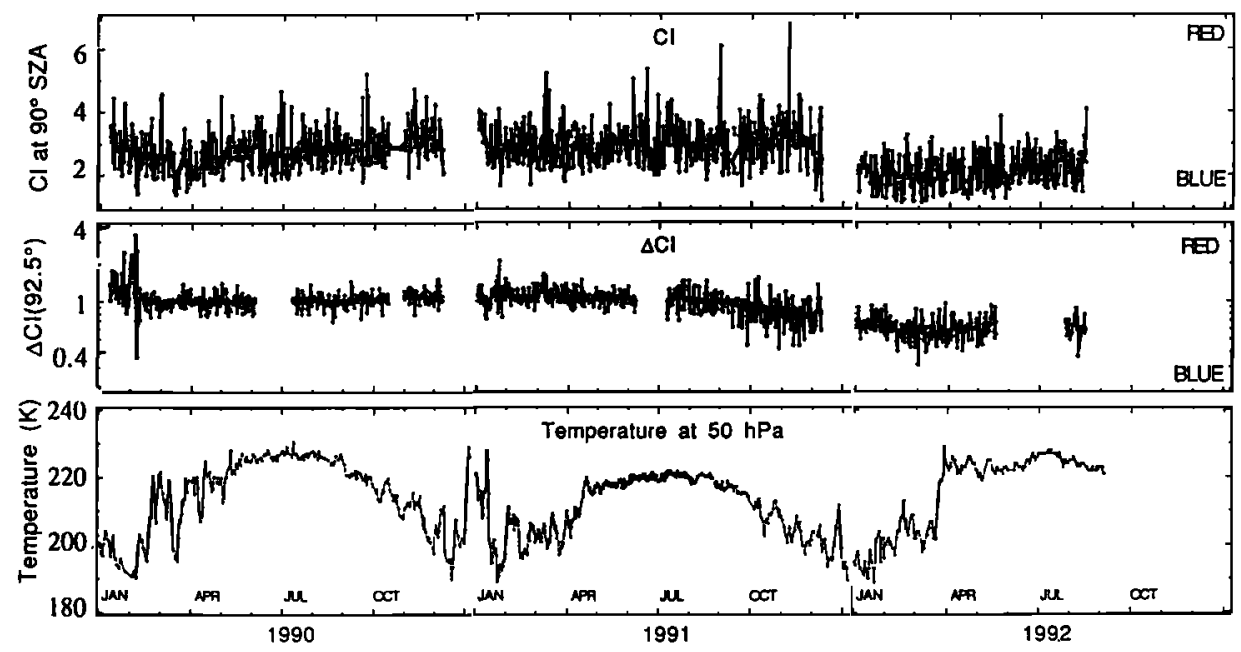

Fig. 1. Twilight sky colour index at $90^{\circ} \mathrm{SZA}$ (upper panel), colour index variation at $92.5^{\circ} \mathrm{SZA}$ (middle panel) and $50 \mathrm{hPa}$ temperature observed at Kiruna (first month) thereafter at Sodankylä from 1990 until 1992.

$\mathrm{CI}\left(90^{\circ}\right), \Delta \mathrm{CI}\left(92.5^{\circ}\right)$, and the temperature at $50 \mathrm{hPa}$ as measured by radio-sondes. There are no data for October 1990, and gaps in CI and $\Delta C I$ in mid-winter and midsummer when the SZA does not reach the required values (the sun does not rise, or does not set). Both morning and evening values of $\mathrm{CI}$ and $\Delta \mathrm{CI}$ are plotted; the lines are 30 day running means.

Changes in cloud cover cause $\mathrm{CI}\left(90^{\circ}\right)$ to fluctuate from day to day by up to $20 \%$ from the mean. Larger positive departures indicate enhancements of multiple scattering as in snow showers or under cumulo-nimbus clouds.

There is a weak minimum in the 30-day running mean of the CI in March 1990, but no apparent change in March 1991. The variation is much weaker than the systematic seasonal minimum seen in Antarctica, which we interpreted as the cleaning of the stratosphere by sedimentation during winter, with the formation of a scattering layer at altitudes between 10 and $14 \mathrm{~km}$ [Sarkissian et al., 1992], consistent with changes seen earlier by SAMS II [McCormick and Trepte, 1987].

After a slight reddening in October and November 1991, CI decreased rapidly to very low values in January and February 1992, and thereafter climbed slowly. This is attributed to the volcanic aerosols resulting from the eruption of Mount Pinatubo in June 1991.

Day-to-day variations of $\Delta \mathrm{CI}\left(92.5^{\circ}\right)$ were generally small, except in winter. This, together with the absence of correlation with spikes in CI, suggests that the tropospheric component of $\mathrm{CI}$ is efficiently eliminated in forming $\Delta \mathrm{CI}$. There were particularly large excursions of $\Delta \mathrm{CI}$, up and down, in January and February 1990. The largest were recorded on 4-6 February during the Cheops III campaign [Pommereau and Schmidt, 1991]. An ozone "mini-hole" was reported, with temperatures in the stratosphere falling to $178 \mathrm{~K}$ [Sarkissian et al., 1991]. Just one event was seen in 1991: on 22-23 January, also associated with a mini-hole event [Goutail et al., 1993].

No large departures from the mean of $\Delta C I$ were recorded at Sodankylä during the winter 1991/92. $\Delta C I$ decreased slowly from September until January, and then remained steady until the end of March. The decline is attributed to the advection of Pinatubo aerosol. In contrast to the reddening reported from Antarctica [Sarkissian et al., 1992], the shift at Sodankylä was to the blue. This suggests that the aerosol layer in the Arctic was at lower altitude than the layer in Antarctica, that is in agreement with lidar observations [Godin et al., 1992; Neuber et al., 1993].

\section{$\triangle \mathrm{CI}$ Observations during EASOE}

Figure 2 shows the records of $\Delta \mathrm{CI}\left(92.5^{\circ}\right)$, temperature at $50 \mathrm{hPa}$ and potential vorticity (PV) at $400 \mathrm{~K}$ isentropic surface at the four SAOZ stations in operation during EASOE. The variations in $\triangle \mathrm{CI}$ are similar at all the stations. Day to day variations are small, never exceeding $25 \%$ (note that the scale is twice that used in figure 1). It would appear that there were no PSCs during EASOE, unless they were masked by the volcanic aerosol. There was no correlation between $\Delta \mathrm{CI}$ and either the temperature at $50 \mathrm{hPa}$ or the potential vorticity on the $400 \mathrm{~K}$ isentropic surface. $\Delta \mathrm{CI}$ are similar outside and inside the polar vortex.

\section{Interpretation of $\Delta \mathrm{CI}$ observations}

The occurrence of PSCs has been attributed to the condensation of nitric acid trihydrate (NAT). The critical temperature at $50 \mathrm{hPa}$ in the lower stratosphere may be as low as 195K, for typical concentrations of nitric acid and water vapour [Hanson and Mauersberger, 1988]. Figure 3-A shows the distribution, up to September 1991, of $\Delta \mathrm{CI}(92.5)$ with the temperature at $50 \mathrm{hPa}$ as measured by radio-sondes over Sodankylä. Large shifts of colour occur only at temperatures below the NAT point ( $192 \mathrm{~K})$. The scattering is clearly associated with PSCs. The distribution thereafter, figure 3-B, shows systematic blue shifts at all temperatures, associated with volcanic aerosols. Added to this systematic blueing, some values at $0.8<\Delta \mathrm{CI}\left(92.5^{\circ}\right)<1.3$ appeared at warm temperatures $(228 \mathrm{~K})$. They are recorded in October 1991 (figure 1). They indicate that the aerosol arrived in patches, as already observed by lidar at middle latitudes [Neuber et al., 1993].

Figure 4-A shows $\Delta \mathrm{CI}(\mathrm{SZA})$ for $93^{\circ}>\mathrm{SZA}>90^{\circ}$ (dots) as recorded from January 1990 until August 1991 compared with model calculations (curves): (a) background aerosol 


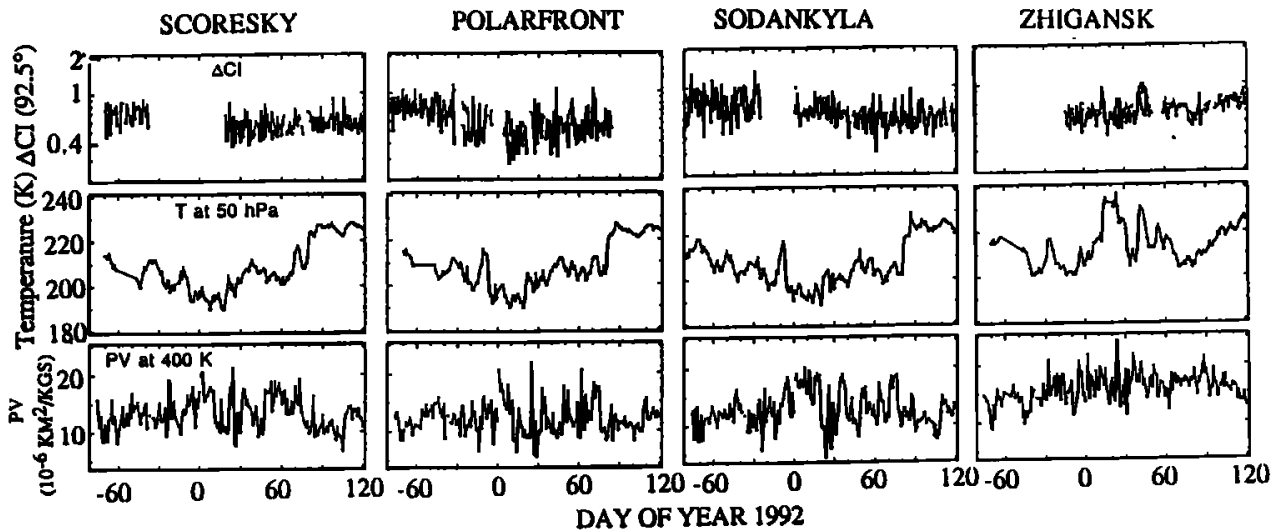

Fig. 2. Colour index variations at $92.5^{\circ} \mathrm{SZA}, 50 \mathrm{hPa}$ temperature and potential voriicity, observed during EASOE at four Arctic stations: a) Scoresbysund, Greenland; b) Polarfront, northern Atlantic; c) Sodankylä, Finland and d) Zhigansk, eastern Siberia.

only (attenuation $0.16 \mathrm{~km}^{-1}$ at ground level, scale height of $2 \mathrm{~km}$ in the troposphere and above, a layer from 6 to $18 \mathrm{~km}$ of about $1.310^{-3} \mathrm{~km}^{-1}$ [tropospheric part from the Handbook of Geophysics, 1965; stratospheric part from SAGE II Stratospheric Aerosol and Gas Experiment, Brogniez et al., 1992]; (b) geometrically thin $(\Delta Z=3 \mathrm{~km})$ and optically thick $(\tau=0.01)$ high altitude PSC centered at $24 \mathrm{~km}$; (c) low altitude $(Z=16 \mathrm{~km})$, geometrically and optically thick $(\Delta Z=7 \mathrm{~km}, \tau=0.01$ ) PSC. Before the eruption (figure 4A), the observed steady $\Delta \mathrm{CI}$ during twilight, as well as large reddenings or blueings caused by dense PSCs, are consistent with the model. After the arrival of the volcanic aerosol (figure 4-B), the observations are well captured by the model by introducing the experimental vertical distributions of optical thickness observed from balloons on the 16th of January and the10th of February 1992 (curves d and e) [Pommereau and Piquard, 1993]. According to the balloon measurements at the end of November, the main aerosol layer was located at about $15 \mathrm{~km}$ with a total optical thickness of 0.056 . By mid-March its altitude was a little higher $(17 \mathrm{~km})$ with a total optical thickness of 0.083 . The shifts to the blue in $\Delta \mathrm{CI}(\mathrm{SZA})$ are broadly consistent with these reports.

In addition, calculations were made using a model containing both a layer of volcanic aerosols and PSCs. The results suggest that the colour shifts may cancel out. A PSC within the aerosol layer (below $22 \mathrm{~km}$ ) would be unnoticed. However, a geometrically thin $(\Delta \mathrm{Z}=1-3 \mathrm{~km})$ and optically
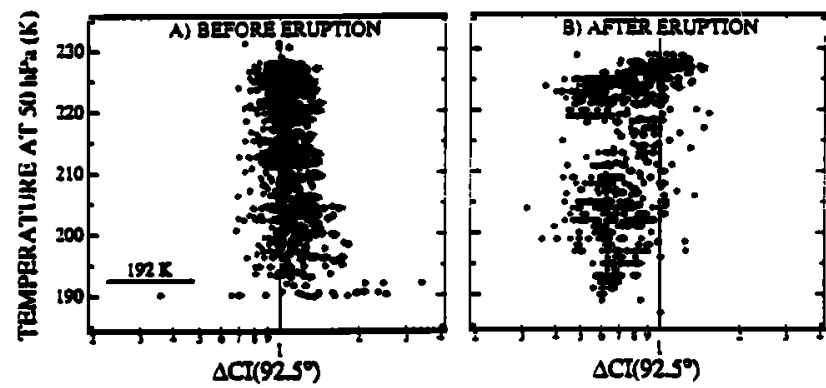

Fig. 3. Relation between colour index variation at $92.5^{\circ}$ and $50 \mathrm{hPa}$ temperature before (A) and after (B) the arrival of volcanic aerosol. Large sky colour shifts toward the red or the blue are observed first at temperature below $192 \mathrm{~K}$ only caused by PSCs-, thereafter systematic blue shifts are observed at all temperatures -caused by volcanic aerosols-. thick ( $\tau>0.01$ ) PSC above $22 \mathrm{~km}$ as observed in 1990 would have resulted in an overall reddening.

According to figure 2, no large red shift of $\Delta \mathrm{CI}\left(92.5^{\circ}\right)$ was seen during EASOE. However, an ozone "mini-hole" and a minimum in $\mathrm{NO}_{2}$ was recorded by the $\mathrm{SAOZ}$ spectrometer at Sodankylä on 29-30 December 1991 [Goutail et al., 1993]. The temperature at $23 \mathrm{~km}$ was $183 \mathrm{~K}$. On these days the sun does not rise above the horizon, and $\Delta \mathrm{CI}\left(92.5^{\circ}\right)$ is not available. Figure 5 shows $\mathrm{CI}(\mathrm{SZA}) / \mathrm{CI}\left(91^{\circ}\right)$ for this event. The pronounced reddening (to a ratio of 1.8 ) on the evening of 29 December, and the contrast between the neutrality of the preceding and succeeding twilight and the volcanic blueing evident earlier and later, clearly indicate the persistent presence of high altitude $(>22 \mathrm{~km})$, geometrically thin $(1-3 \mathrm{~km})$ and optically thick (optical thickness $>0.01$ ) PSCs.

\section{Concluding remarks}

Colour indices derived from twilight sky measurements at four stations near the Arctic circle have made it possible to follow the development of the volcanic aerosol layer formed after the eruption of Mount Pinatubo. The first

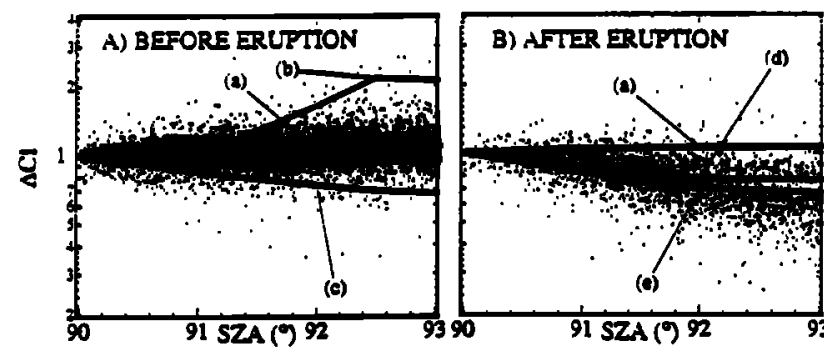

Fig. 4. Observed colour index variations during twilight ( $\triangle C$ C) before (A) and after (B) the arrival of aerosol iy: September 1991, compared to calculations by a model including: (a) background aerosol only; (b) thin $(\Delta Z=3 \mathrm{~km})$ and high altitude $(24 \mathrm{~km})$ optically thick $(\tau=0.01)$ PSC; (c) thick $(7 \mathrm{~km})$ and low altitude $(16 \mathrm{~km})$ optically thick ( $\tau=$ $0.01)$ PSC; (d) an aerosol layer at $15 \mathrm{~km}(\tau=0.056, \Delta Z=5$ $\mathrm{km}$ ) as observed from a balloon on 16 January 1992 and (e) at $17 \mathrm{~km}(\tau=0.083, \Delta Z=5 \mathrm{~km})$ as on 10 February 1992 . Without volcanic aerosol, the colour index remains almost constant during twilight, except in presence of PSC. The aerosol layer shifts the index toward the blue at large SZA. 


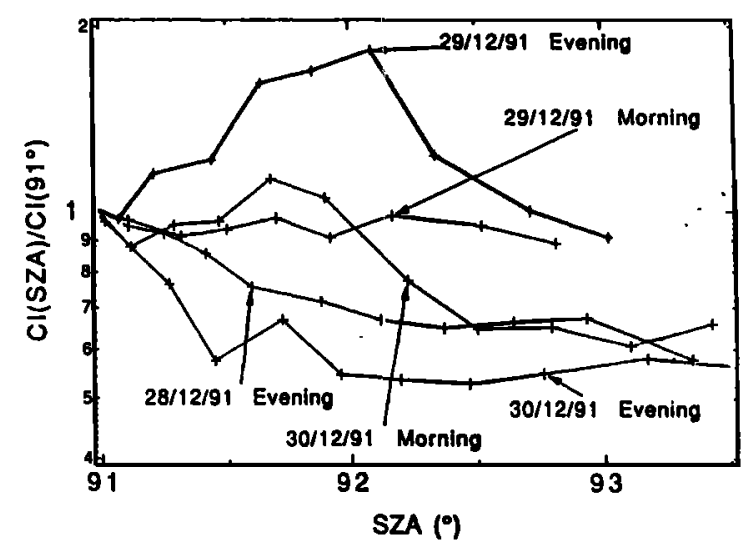

Fig. 5. Twilight colour index variations at Sodankylä from 28 until 30 December 1992, normalised at $91^{\circ} \mathrm{SZA}$ instead of $90^{\circ}$, since the sun remains below the horizon on these days. The large reddening detected on December 29 on the evening and the lesser reddening seen on the previous and following mornings were caused by a dense PSC at around $23 \mathrm{~km}$. This was the only PSC detected during winter 91/92.

detection of aerosol at $66^{\circ} \mathrm{N}$ was in September 1991. The layer thickened progressively into January 1992, but there was little further change until mid-March.

The indices produced routinely gave no indications of PSCs. Calculations suggest that at low altitudes, PSCs would have gone unnoticed because their effects would have been masked by the volcanic aerosol. High-altitude thick PSCs were detected over Sodankylä on 28-29 December 1991 using modified CI ratios. The winter of the EASOE campaign was thus markedly different from that of 1990/91, when PSCs were observed frequently.

Acknowledgements. This work was supported by the Commission of the European Communities DG XII (Grant STEP-CT91-0141), the Programme d'Atmosphère Moyenne of CNRS and the Ministère de l'Environnement. The SAOZ instruments were run at Scoresbysund by the Danish Meteorological Institute (DMI), on-board the ship Polarfront by the Norwegian Institute for Air Research (NILU) and at Zhigansk by the Central Aerological Observatory (CAO) of Russia. Potential vortıcities were calculated by B. Knudsen from ECMWF data collected at NILU. Their contributions are gratefully acknowledged. The authors would like to express their gratitude to J. C. Farman for his help for correcting the manuscript.

\section{References}

Brogniez C., R. Santer, B.S. Diallo, M. Herman, J. Lenoble and $H$. Jäger, Comparative observations of stratospheric aerosols by ground-based lidar, balloon-borne polarimeter and satellite solar occultation, J. Geophys. Res. 97, 20805-20823, 1992.

Godin S., A. Sarkissian, C. David, G. Mégie, J.P. Pommereau, F. Goutail, P. Aimedieu, J. Piquard, E. Le Bouar, L. Stefanutti, M. Morandi and M. del Guasta, Systematic stratospheric observations on the Antarctic continent at Dumont d'Urville, Proc. Ouad. Ozone Symp, 1993 , in press.

Goutail F., J.P. Pommereau and A. Sarkissian, Four years of ground-based total ozone measurements by visible spectrometry in Antarctica, Proc. Ouad. Ozone Symp. 1993, in press.

Goutail F., J.P. Pommereau, A. Sarkissian, E. Kyro and V. Dhorokov, Total nitrogen dioxide at the Arctic polar circle since 1990, this issue.

Handbook of Geophysics and Space Environments, Mc Graw-Hill, New York, 1965.

Hanson, D. and K. Mauersberger, Laboratory studies of the nitric acid trihydrate: 1mplications for the south polar stratosphere, Geophys. Res. Lett., 15, 855-858, 1988.

McCormick M.P. and C.R. Trepte, Polar stratospheric optical depth observed between 1978 and 1985, J. Geophys. Res. 92, 4297-4306, 1987.

Neuber R., G. Beyerle, G. Fiocco, A. di Sarra, K.H. Fricke, C. David, S. Godin, L. Stefanutti, G. Vauhan and J.P. Wolf, Latitudinal distribution of stratospheric aerosols during the EASOE winter 1991/92, this issue.

Pommereau, J. P., and F. Goutail, $\mathrm{O}_{3}$ and $\mathrm{NO}_{2}$ ground-based measurements by visible spectrometry during Arctic winter and spring 1988, Geophys. Res. Lett., 15, 891894, 1988.

Pommereau J.P.and U. Schmidt, CHEOPS III: an ozone research programme in the Arctic winter 1989/90, Geophys. Res. Lett., 18, 759-761, 1991.

Pommereau J.P. and J. Piquard, Stratospheric minor species vertical distribution during polar winter by balloon borne UV-visible spectrometry, this issue.

Sarkissian A., J.P. Pommereau and F. Goutail, Identification of polar stratospheric clouds from the ground by visible spectrometry, Geophys. Res. Lett., 18, 779-782, 1991.

Sarkissian A., J.P. Pommereau and F. Goutail, PSC and volcanic aerosol routine observations in Antarctica by UV-visible ground-based spectrometry, Proc. Quad Ozone Symp., 1993, in press.

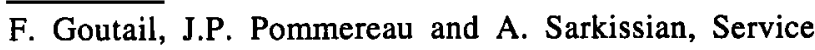
d'Aéronomie, Verrières-le-Buisson Cedex, 91371, France.

Received: December 4, 1992 Revised: May 7, 1993

Accepted: November 1, 1993 